\title{
Conditional Asset Pricing and Stock Market Anomalies in Europe
}

Citation for published version (APA):

Bauer, R. M. M. J., Cosemans, M. M. J. E., \& Schotman, P. C. (2010). Conditional Asset Pricing and Stock Market Anomalies in Europe. European Financial Management, 16(2), 165-190. https://doi.org/10.1111/j.1468-036X.2008.00453.x

Document status and date:

Published: 01/03/2010

DOI:

10.1111/j.1468-036X.2008.00453.x

Document Version:

Publisher's PDF, also known as Version of record

Document license:

Taverne

Please check the document version of this publication:

- A submitted manuscript is the version of the article upon submission and before peer-review. There can be important differences between the submitted version and the official published version of record.

People interested in the research are advised to contact the author for the final version of the publication, or visit the DOI to the publisher's website.

- The final author version and the galley proof are versions of the publication after peer review.

- The final published version features the final layout of the paper including the volume, issue and page numbers.

Link to publication

\footnotetext{
General rights rights.

- You may freely distribute the URL identifying the publication in the public portal. please follow below link for the End User Agreement:

www.umlib.nl/taverne-license

Take down policy

If you believe that this document breaches copyright please contact us at:

repository@maastrichtuniversity.nl

providing details and we will investigate your claim.
}

Copyright and moral rights for the publications made accessible in the public portal are retained by the authors and/or other copyright owners and it is a condition of accessing publications that users recognise and abide by the legal requirements associated with these

- Users may download and print one copy of any publication from the public portal for the purpose of private study or research.

- You may not further distribute the material or use it for any profit-making activity or commercial gain

If the publication is distributed under the terms of Article $25 \mathrm{fa}$ of the Dutch Copyright Act, indicated by the "Taverne" license above, 


\title{
Conditional Asset Pricing and Stock Market Anomalies in Europe
}

\section{Rob Bauer}

Maastricht University and NETSPAR

E-mail: R.Bauer@finance.unimaas.nl

\section{Mathijs Cosemans}

Maastricht University, P.O. Box 616, 6200 MD Maastricht, Netherlands

E-mail: M.Cosemans@finance.unimaas.nl

\section{Peter C. Schotman}

Maastricht University, CEPR and NETSPAR

E-mail:P.Schotman@finance.unimaas.nl

\begin{abstract}
This study provides European evidence on the ability of static and dynamic specifications of the Fama-French (1993) three-factor model to price 25 size$B / M$ portfolios. In contrast to US evidence, we detect a small-growth premium and find that the size effect is still present in Europe. Furthermore, we document strong time variation in factor risk loadings. Incorporating these risk fluctuations in conditional specifications of the three-factor model clearly improves its ability to explain time variation in expected returns. However, the model still fails to completely capture cross-sectional variation in returns as it is unable to explain the momentum effect.
\end{abstract}

Keywords: conditional asset pricing, time-varying risk, stock market anomalies

JEL classification: $G 12, G 14$

\section{Introduction}

The Capital Asset Pricing Model (CAPM) has been one of the cornerstones of modern finance since its development in the 1960s. However, starting in the eighties a number of patterns in the cross-section of average returns have been detected that question the validity of the model, including the size effect (Banz, 1981), value premium (Basu, 1977) and momentum effect (Jegadeesh and Titman, 1993). In addition, Fama and

We are grateful to an anonymous referee, John Doukas (the editor), Rik Frehen, Roy Hoevenaars, Robert Korajczyk, Zhan Onayev (the EFMA discussant), Jean-Pierre Urbain and seminar participants at Maastricht University, Robeco Asset Management, and the 2007 EFMA Meetings in Vienna, for helpful comments. Correspondence: Mathijs Cosemans. 
French (1992) show that size and book-to-market equity (B/M) are better able to capture the cross-section of returns than market beta. While the Fama-French (1993) three-factor model seems to be able to repair most of the cracks in the building of modern finance, Fama and French (1996) show that it is unable to explain the momentum effect. Apart from these cross-sectional anomalies, prior research has also found that firm characteristics (Lewellen, 1999) and macroeconomic variables (Ferson and Harvey, 1999) predict significant time variation in expected returns on size-B/M sorted portfolios.

Rational asset pricing theory posits that these variables have predictive power because they capture information about time-varying risk. Accordingly, static models fail to explain the cross-section of average returns because they ignore risk dynamics across stocks. Therefore, much recent work has focused on conditional asset pricing models, in which risk loadings are allowed to vary over time. Since the empirical results of these studies are mixed and primarily based on US data, our main goal in this paper is to provide out-of-sample evidence on the performance of the conditional three-factor model. Specifically, we test whether factor loadings are time-varying and if so, to what extent dynamic specifications of the model explain time variation and cross-sectional variation in returns on 25 size-B/M portfolios constructed using stocks from 16 European markets.

We first examine the predictive power of a set of macroeconomic and portfoliospecific variables for European size-B/M portfolios. Next, we test whether portfolio betas are time-varying by modelling variation in risk loadings as a function of the predictive variables. Subsequently, we investigate whether conditional models completely explain conditional expected returns, i.e. whether conditional alphas are zero. We also test the weaker hypothesis that conditional alphas are unrelated to the predictors. Finally, we combine the time series analysis with the cross-sectional framework developed by Brennan et al. (1998). Specifically, we calculate risk-adjusted returns and perform a cross-sectional analysis to examine whether cross-sectional variation in pricing errors is related to size, $\mathrm{B} / \mathrm{M}$ and past returns.

We extend existing work in several ways. First, by using a large data set of European stocks we provide out-of-sample empirical evidence on the time-varying behaviour of risk and the performance of conditional asset pricing models. ${ }^{1}$ Following Fama and French (2006), we construct the 25 size-B/M portfolios and the risk factors using merged data from the markets of interest, which enables us to form well-diversified portfolios. Thus, we adopt a pan-European approach motivated by the increasing integration between European markets that started in the mid-1980s, which coincides with the beginning of our sample (Bekaert et al., 2005; Eiling and Gerard, 2006). In contrast, Fama and French (1998) examine the presence of a value premium in international markets by forming portfolios for each country separately. An important drawback of this method is that for many countries the resulting portfolios only contain a few stocks and, consequently, that idiosyncratic risk is not fully eliminated.

We find that for our sample period the explanatory power of the three-factor model in Europe is higher than in the USA, providing further support for the pan-European perspective we take. Rouwenhorst (1998) also takes a pan-European perspective by aggregating stocks into momentum portfolios. He confirms that the profitability of

\footnotetext{
${ }^{1}$ In a recent paper, Schrimpf et al. (2007) provide empirical evidence on the performance of conditional asset pricing models for the German stock market.
} 
momentum strategies is not driven by country effects. Heston et al. (1999) document a negative relation between European stock returns and firm size.

Our work contributes to these studies as follows. First, we allow for time-varying risk in a conditional three-factor model whereas Fama and French, Heston et al. and Rouwenhorst control for risk using unconditional two-factor models. Second, we focus on multiple anomalies simultaneously while they only consider a single anomaly. Third, we examine a more recent time period, which includes the burst of the tech bubble.

On the methodology side, the time series tests we employ avoid the problems associated with the cross-sectional tests discussed by Lewellen et al. (2007) because they impose the theoretical restrictions that risk premia equal expected excess factor returns and that the zero-beta rate equals the risk-free rate.

Our empirical results show substantial differences between US and European data, which motivates the analysis of the performance of conditional asset pricing models in Europe. In particular, we find that the size effect, which has vanished in the USA after its discovery (Cochrane, 2005), is still present in Europe. In addition, our time-series analysis reveals that the unconditional three-factor model leaves significant pricing errors. Strikingly, the small-growth portfolio, known to be hard to price in the USA because it generates significant negative alphas, produces significant positive pricing errors in Europe. We also find that macroeconomic and portfolio-specific variables have substantial predictive power for returns on the size-B/M portfolios. Using these variables as instruments for conditional betas, we document strong evidence of time-varying risk. Incorporating these fluctuations in risk improves the performance of the three-factor model in explaining time variation in portfolio returns. Nevertheless, even after allowing for variation in loadings the three-factor model does not completely explain conditional expected returns as pricing errors for some portfolios remain predictable.

Our cross-sectional findings show that the rejection of the three-factor model is due to strong momentum effects in returns on the 25 size-B/M portfolios. Both the static and dynamic three-factor model do not capture the explanatory power of past return (momentum) variables for the cross-section of portfolio returns. Our European evidence supports the US findings of Ferson and Harvey (1999), Avramov and Chordia (2006), Lewellen and Nagel (2006) and Petkova and Zhang (2005). In particular, although betas do vary over time, these fluctuations are too small to explain the momentum effect.

The remainder of this paper is organized as follows. Section 2 provides the rationale for conditional asset pricing models and reviews existing empirical evidence. Section 3 explains our methodology and section 4 describes the data set. In section 5 we present our empirical findings and discuss the robustness of the results. Section 6 concludes.

\section{Conditional Asset Pricing: Theory and Evidence}

Proponents of conditional asset pricing argue that the failure of unconditional models to explain the cross-section of average returns might be due to their assumption that risk loadings remain constant over time. Santos and Veronesi (2004) show within a general equilibrium model that market betas vary substantially when the covariation between a firm's cash flows and the aggregate economy is large. If true betas are time-varying, static models are misspecified and give an incomplete description of stock returns. Indeed, abundant empirical evidence of time variation in beta has been found, which has motivated the development of conditional models that allow factor loadings to vary. 
Hansen and Richard (1987) provide theoretical support for dynamic models by showing that a conditional CAPM can hold perfectly even if its unconditional counterpart fails.

According to conditional asset pricing theory, a significant relation between predictive variables and the time series and cross-section of returns must be due to their association with risk. In particular, the variables must contain information about time variation in risk, and consequently, in expected returns. Furthermore, differences in risk dynamics across stocks induce cross-sectional variation in conditional expected returns. This implies that the power of the predictors should disappear once we adequately control for fluctuations in risk. Gomes et al. (2003) show theoretically that the ability of size and $\mathrm{B} / \mathrm{M}$ to explain cross-sectional variation in returns is due to their correlation with the true conditional market beta. Zhang (2005) extends this work and argues that because of costly reversibility of capital value firms have countercyclical betas while betas of growth stocks are procyclical. Because the price of risk is also countercyclical his model can explain the value premium within a rational framework.

In contrast, the mispricing view put forward by Lakonishok et al. (1994) and Daniel and Titman (1997) asserts that the significant association between predictive variables and expected returns is related to investor cognitive biases. Specifically, this story says that the predictors contain information about mispricing of securities and, consequently, that their predictive power will persist even when risk fluctuations are taken into account.

Hitherto, empirical evidence on the performance of conditional asset pricing models is inconclusive and primarily based on US data. Favourable results are documented by Jagannathan and Wang (1996), who find that a conditional CAPM extended by a proxy for the return on human capital leaves insignificant pricing errors when applied to portfolios sorted on size and beta. Lewellen (1999) shows that after controlling for its role as determinant of conditional betas, $\mathrm{B} / \mathrm{M}$ contains little incremental information about time variation in expected returns. Ferson and Harvey (1998) find that the crosssectional explanatory power of firm-specific attributes like book-to-market mainly arises from their role as instruments for risk instead of their relation to mispricing. Wu (2002) argues that a conditional three-factor model captures momentum and reversal effects in US stock returns when the assumption of a linear relation between conditioning variables and betas is relaxed. ${ }^{2}$

More recently, Ang and Chen (2007) document strong evidence of time variation in betas of portfolios sorted on B/M and find that a conditional CAPM in which timevarying betas are treated as latent state variables is able to capture the book-to-market effect. Adrian and Franzoni (2005) propose a conditional CAPM in which investors learn about unobserved time-varying risk by observing realizations of returns. Their learning CAPM cannot be rejected when applied to size-B/M portfolios.

In contrast, results found by other studies are less favourable. Ferson and Harvey (1999) show that even in a conditional three-factor model proxies for time variation in expected returns based on macroeconomic instruments have significant cross-sectional explanatory power for returns on size-B/M sorted portfolios. Petkova and Zhang (2005) confirm empirically the theoretical prediction of Zhang (2005) that value firms are riskier than growth firms in economic downturns when the expected market premium is high. However, they note that the covariance between beta and the price of risk is

\footnotetext{
${ }^{2} \mathrm{Wu}$ (2002) tests the conditional linear-exposure FF model using standard OLS time-series regressions but employs a cross-sectional GMM test for the conditional nonlinear-exposure FF model. This makes it difficult to determine whether his results are driven by the difference in model specification or by a difference in the power of both tests.
} 
too small to explain the magnitude of the value premium. Lewellen and Nagel (2006) also find that this covariance is insufficient to explain the large unconditional alphas produced by book-to-market and momentum portfolios.

Using individual stocks as test assets, Avramov and Chordia (2006) find that conditional multifactor models can explain size and value anomalies but are unable to capture momentum and turnover effects in returns. Lewellen et al. (2007) argue that the favourable evidence on the ability of conditional models to price size-B/M sorted portfolios is largely due to the low power of the cross-sectional tests employed in many papers. In particular, they show that when risk premia are unrestricted, any factor that is only weakly correlated with SMB and HML will price the size-B/M portfolios due to their strong factor structure.

\section{Methodology}

\subsection{Time-series test methodology}

The conditional three-factor model can be written as

$$
E_{t}\left(R_{i t+1}\right)=\alpha_{i t}+\sum_{k=1}^{3} \beta_{i k t} E_{t}\left(F F_{k t+1}\right),
$$

where $R_{i}$ is the excess return on asset $i, F F$ is a vector containing the three FamaFrench factors $R_{M}, S M B$ and $H M L, E_{t}(\cdot)$ is the conditional expectation, given the public information set at time $t$, and $\beta_{i k t}$ is the conditional beta with respect to the $k$ th factor.

Following Shanken (1990), we model time variation in alphas and betas by allowing them to depend linearly on a set of predetermined instruments (conditioning variables). ${ }^{3}$ This approach explicitly links conditional betas to observable state variables, consistent with the economic motivation for conditional models. In particular, in this framework conditional betas are given by

$$
\beta_{i k t}=\gamma_{i k 0}+\gamma_{i k 1} Z_{i t},
$$

where $\gamma_{i k 0}$ is a scalar, $\gamma_{i k l}$ a vector of $N$ parameters and $Z_{i t}$ a vector of $N$ instruments. We test the hypothesis that risk loadings are constant over time by examining whether the $\gamma_{i k 1}$ parameters are equal to zero. Analogous to the specification of conditional betas, the conditional alpha is

$$
\alpha_{i t}=\alpha_{i 0}+\alpha_{i 1} W_{i t}
$$

where $W_{i t}$ is a vector of instruments for alpha.

We test the hypothesis that the three-factor model completely explains conditional expected portfolio returns, which corresponds to the null hypothesis that the conditional alpha in equation (1) is equal to zero. Thus, rational asset pricing theory predicts that the $\alpha_{i 0}$ and $\alpha_{i 1}$ parameters in equation (3) should all be zero. We also test the weaker condition that alpha is constant over time, i.e. that $\alpha_{i 1}$ is zero. Under this null hypothesis

\footnotetext{
${ }^{3}$ Other approaches to allow for time variation in betas include estimating conditional betas using short-window regressions (Lewellen and Nagel, 2006), rolling regressions (Fama and French, 1997), and modelling beta as a latent autoregressive process (Ang and Chen, 2007 and Ammann and Verhofen, 2007). In contrast to our approach, these methods do not explicitly link risk dynamics to business cycle variations.
} 
the instruments do not predict expected portfolio returns after their role as instrumental variables for conditional risk loadings is taken into account. The alternative hypothesis is that the conditioning variables are related to time-varying mispricing.

Combining equations (1), (2), and (3) leads to the econometric model

$$
R_{i t+1}=\alpha_{i 0}+\alpha_{i 1} W_{i t}+\left(\gamma_{i k 0}+\gamma_{i k 1} Z_{i t}\right) F F_{k t+1}+\varepsilon_{i t+1} .
$$

We evaluate alternative model specifications based on (4), with both constant and timevarying alphas and betas and various combinations of instrumental variables, using the adjusted $\mathrm{R}^{2}$ and Akaike information criterion.

\subsection{Cross-sectional framework}

In the cross-sectional tests we examine the predictive power of various non-risk characteristics. Rational asset pricing theory predicts that non-risk security characteristics like size and B/M should not have any cross-sectional explanatory power for returns incremental to the risk factors included in the asset pricing model. This hypothesis can be tested using the following equation,

$$
R_{i t+1}=c_{0 t+1}+\sum_{k=1}^{3} \lambda_{k t+1} \hat{\beta}_{i k t}+\sum_{m=1}^{M} c_{m t+1} P_{m i t}+v_{i t+1},
$$

where $\lambda_{k}$ is the risk premium for factor $k, c_{m}$ is the reward to non-risk characteristic $m$ and $P_{m i t}$ is the value of characteristic $m$ for portfolio $i$ at time $t$. The null hypothesis that expected returns on portfolio $i$ only depend on its sensitivity to the risk factors in the model, measured by $\hat{\beta}_{i k}$, implies that all loadings $c_{m}$ on the non-risk factors must be zero. As noted by Berglund and Knif (1999), the Fama-MacBeth (1973) two-step procedure commonly used to test this hypothesis suffers from an errors-in-variables problem, since the betas included as regressors in the second stage cross-sectional regressions are estimated with error in the time-series regressions.

In order to circumvent this problem we follow Brennan et al. (1998) and Avramov and Chordia (2006) by regressing risk-adjusted returns obtained from the time-series regression (4) on the portfolio characteristics size, book-to-market and cumulative past returns. The estimated risk-adjusted return is given by

$$
R_{i t+1}^{*} \equiv R_{i t+1}-\sum_{k=1}^{3} \hat{\beta}_{i k t} F F_{k t+1} .
$$

We calculate the risk-adjusted return $R_{i t+1}^{*}$ in (6) as the sum of the intercept $\alpha_{i 0}$ and the error term $\epsilon_{i t+1}$ obtained from the first-pass time-series regression (4). This riskadjusted return is then used as dependent variable in the second-stage cross-sectional regression,

$$
R_{i t+1}^{*}=c_{0 t+1}+\sum_{m=1}^{M} c_{m t+1} P_{m i t}+\eta_{i t+1} .
$$

This approach avoids any errors-in-variables bias because betas estimated in the timeseries regressions do not show up as regressors in the cross-sectional regressions. The relation between the time-series tests and the cross-sectional analysis is as follows: if the time-series regressions identify significant pricing errors, the cross-sectional tests reveal whether this mispricing is related to size, value or momentum effects. 
We test the hypothesis that expected returns only depend on the risk characteristics of returns by calculating the Fama-MacBeth (FM) estimator for the non-risk characteristics, which is the time-series average of the monthly parameter estimates $c_{m t}$. The standard error of the FM estimator is calculated from the time series of these monthly estimates.

\section{Data and Descriptive Statistics}

The MSCI data set we use consists of the monthly return and book and market value for a sample of common stocks from 16 European countries that covers approximately $80 \%$ of European stock market capitalization. All variables are denominated in euros. ${ }^{4}$ The raw data set includes 2503 firms and covers the period from February 1985 to June 2002. The stocks are listed on the exchanges of Austria, Belgium, Denmark, Finland, France, Germany, Greece, Ireland, Italy, The Netherlands, Norway, Portugal, Spain, Sweden, Switzerland and the UK. The number of stocks per country ranges from 37 for Ireland to 519 for the UK. The MSCI data is free from survivorship bias as it includes historical data for firms that are delisted over time. Furthermore, historical data for newly included stocks is not added to the data set, which should prevent any backfilling bias.

A stock is used in our analysis for a given month $t$ if it satisfies the following criteria: (i) data should be available in month $t-1$ for size as measured by market capitalization and for the book-to-market ratio. This condition is imposed because returns for month $t$ are calculated for portfolios formed at the end of month $t-1$ on size and bookto-market; (ii) its book-to-market equity is non-negative. This last requirement follows Fama and French (1993). The screening process leads to a sample that contains on average 1315 stocks per month. The total number of stocks over the full sample period is 2165 . Since we need portfolio returns over the past 12 months to calculate cumulative lagged returns as a proxy for momentum, the analysis starts in February 1986 and ends in June 2002.

Our test assets are 25 portfolios formed on size and B/M, which have become standard in asset pricing tests after the failure of CAPM to explain size and B/M effects in returns. Following Fama and French (2006), we use merged data from all countries for constructing the portfolios. Table 1 reports the size and B/M characteristics of the 25 European portfolios. We also show the characteristics of the 25 US size-B/M portfolios for the same period. ${ }^{5}$ To facilitate comparison, we express the market capitalization of the European portfolios in US dollars. Although these statistics show that the firms in the smallest quintile of the European portfolios are somewhat larger than those in the corresponding US quintile, in general the size and B/M characteristics of the European sample closely resemble those of the US portfolios. Thus, the relative interpretation of small and large firms is similar in both samples. ${ }^{6}$

\footnotetext{
${ }^{4}$ Converting local currency returns to returns in one base currency follows previous international asset pricing studies (e.g., Fama and French (1998) and Rouwenhorst (1998)). In addition, in the robustness section we eliminate any country tilts in the portfolios. As a result, even if exchange rate risk plays a role, it affects each portfolio in a similar way. Therefore, our results are not affected by exchange rate risk.

${ }^{5}$ Data for the 25 US size-B/M portfolios are obtained from Kenneth French's data library: http://mba.tuck.dartmouth.edu/pages/faculty/ken.french/data_library.html

${ }^{6} \mathrm{In}$ the robustness section we purge the size and B/M characteristics of each firm from country effects before constructing the portfolios. This ensures that also within Europe firm size and $\mathrm{B} / \mathrm{M}$ are comparable across countries.
} 
Table 1

Characteristics of 25 portfolios formed on size and B/M: Europe and the USA

This table presents average size and book-to-market characteristics of 25 size-B/M portfolios for the period February 1986 through June 2002. The portfolios are constructed by sorting stocks independently into size and $\mathrm{B} / \mathrm{M}$ quintiles. The 25 size-B/M portfolios are then formed as the intersections of the five size and the five $\mathrm{B} / \mathrm{M}$ quintiles. The left hand side of the table reports average market capitalisation in billions of US dollars and average $\mathrm{B} / \mathrm{M}$ ratio for the 25 European portfolios. The right hand side of the table presents average market capitalisation in billions of US dollars and the average $\mathrm{B} / \mathrm{M}$ ratio for the 25 US portfolios.

\begin{tabular}{|c|c|c|c|c|c|c|c|c|c|c|}
\hline \multirow[b]{2}{*}{ Size quintile } & \multicolumn{10}{|c|}{ Book-to-market equity $(\mathrm{B} / \mathrm{M})$ quintiles } \\
\hline & Low & 2 & 3 & 4 & High & Low & 2 & 3 & 4 & High \\
\hline & \multicolumn{5}{|c|}{ Europe } & \multicolumn{5}{|c|}{ USA } \\
\hline & \multicolumn{5}{|c|}{ Average market cap ( $\$$ billions) } & \multicolumn{5}{|c|}{ Average market cap ( $\$$ billions) } \\
\hline Small & 0.11 & 0.11 & 0.11 & 0.11 & 0.09 & 0.05 & 0.06 & 0.05 & 0.05 & 0.04 \\
\hline 2 & 0.29 & 0.29 & 0.30 & 0.29 & 0.28 & 0.27 & 0.27 & 0.28 & 0.27 & 0.27 \\
\hline 3 & 0.61 & 0.61 & 0.62 & 0.60 & 0.60 & 0.68 & 0.69 & 0.69 & 0.70 & 0.72 \\
\hline 4 & 1.50 & 1.46 & 1.48 & 1.46 & 1.42 & 1.84 & 1.82 & 1.84 & 1.86 & 1.84 \\
\hline \multirow[t]{2}{*}{ Big } & 17.01 & 10.97 & 8.02 & 6.50 & 6.33 & 16.96 & 12.22 & 10.69 & 8.39 & 8.03 \\
\hline & \multicolumn{5}{|c|}{ Average $\mathrm{B} / \mathrm{M}$ ratio } & \multicolumn{5}{|c|}{ Average $\mathrm{B} / \mathrm{M}$ ratio } \\
\hline Small & 0.16 & 0.35 & 0.54 & 0.79 & 2.03 & 0.21 & 0.43 & 0.59 & 0.77 & 1.40 \\
\hline 2 & 0.17 & 0.35 & 0.53 & 0.78 & 1.71 & 0.20 & 0.40 & 0.57 & 0.75 & 1.22 \\
\hline 3 & 0.17 & 0.35 & 0.53 & 0.77 & 1.53 & 0.20 & 0.39 & 0.56 & 0.77 & 1.19 \\
\hline 4 & 0.17 & 0.35 & 0.53 & 0.77 & 1.40 & 0.20 & 0.40 & 0.57 & 0.78 & 1.17 \\
\hline Big & 0.09 & 0.35 & 0.53 & 0.77 & 1.40 & 0.19 & 0.39 & 0.56 & 0.77 & 1.11 \\
\hline
\end{tabular}

The upper left corner of Table 2 presents average monthly returns for the 25 European size-B/M portfolios. For comparison, in the upper right corner we also report statistics for the $25 \mathrm{US}$ size-B/M portfolios for the same period. Strikingly, in the European sample the small growth portfolio (S1/B1) has the highest average return. In contrast, Fama and French (1996) find for the USA that the return on the small growth portfolio is the lowest of all 25 portfolios, which is confirmed by the statistics we report for the US portfolios. Table 2 also shows the presence of a size effect in the European sample, which is absent in the US data. The value premium is positive in both samples but insignificant. Overall, Table 2 reveals important differences between US and European data, which motivates our analysis of the performance of conditional asset pricing models in Europe.

An important issue when applying asset pricing models to European stock markets is whether country-specific or pan-European versions of the models should be used. Bekaert et al. (2005) and Eiling and Gerard (2006) find evidence of capital market integration between European markets from the mid 1980s onwards, which coincides with the beginning of our sample period. This motivates the construction of the FamaFrench risk factors on a pan-European level, consistent with our portfolio formation procedure. We choose the MSCI Europe index as a proxy for the market portfolio because of its broad coverage of European stock market capitalization and subtract the three-month German FIBOR rate as a proxy for the risk-free rate to obtain the 


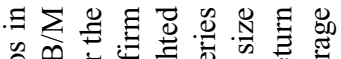

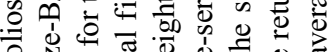

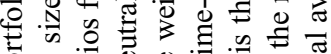

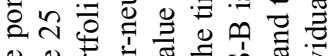

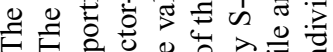
$F F$

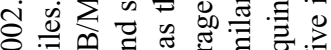

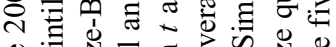

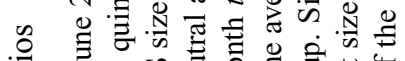

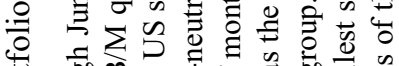

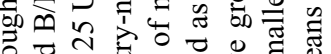

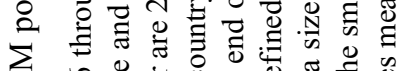

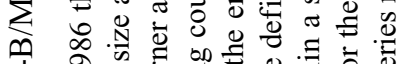

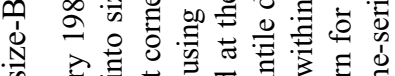

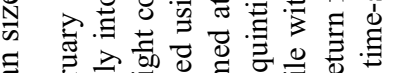

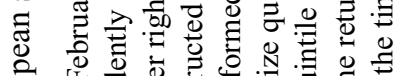

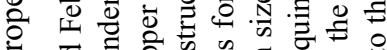

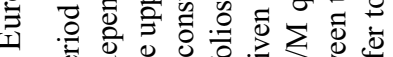

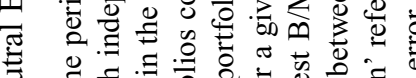

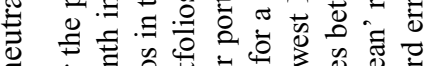

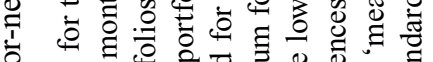

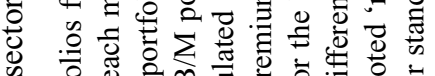

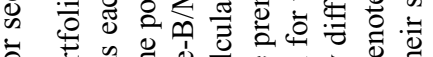

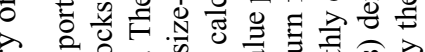

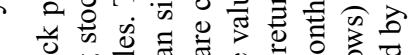
迸.

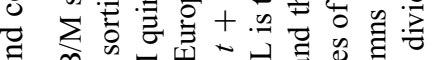
击

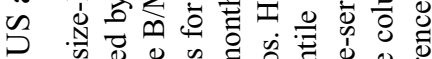

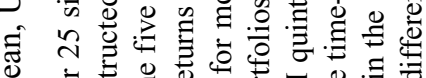

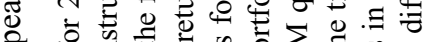
家

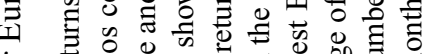
o

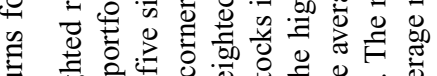

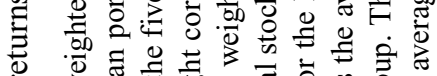

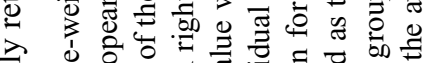

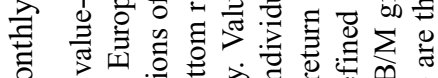

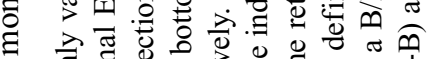

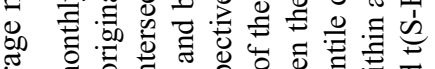

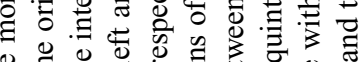

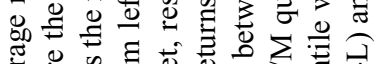

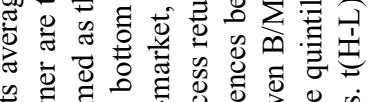

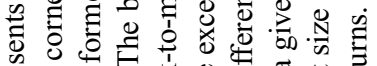

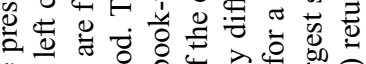

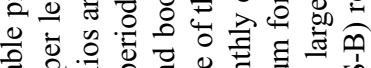

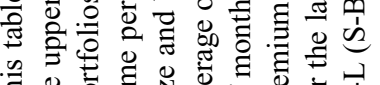

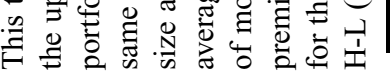

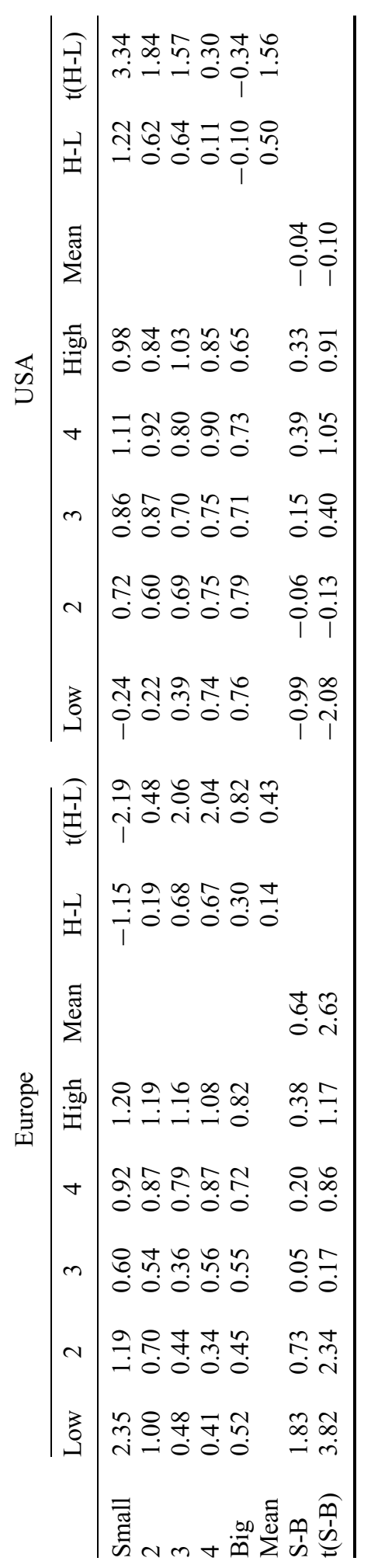




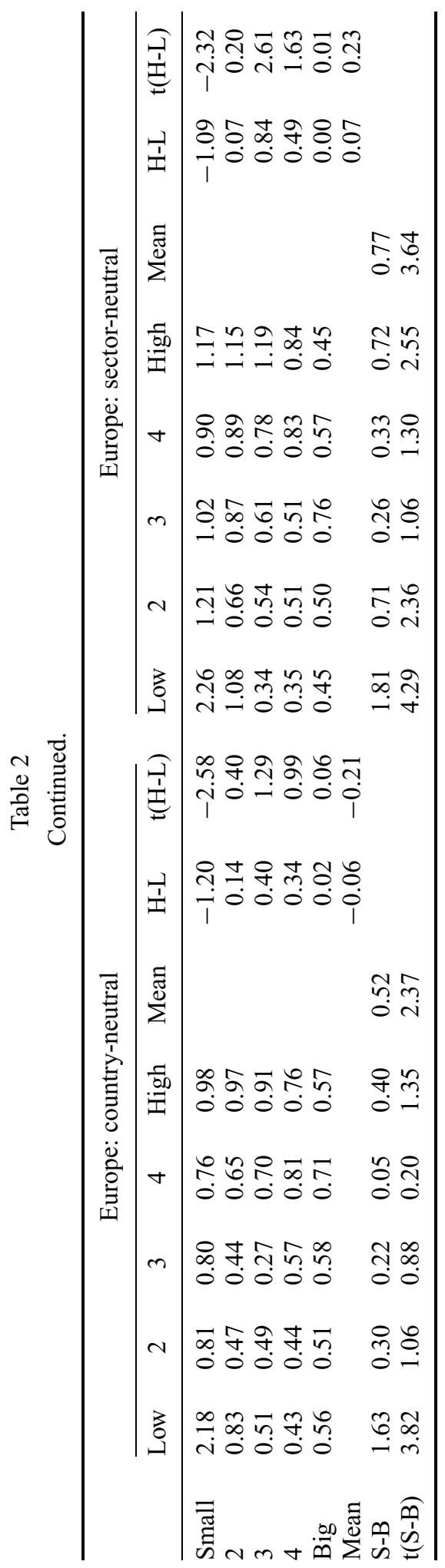


market premium $R_{M}$. We follow the procedure outlined by Fama and French (1993) for constructing the SMB and HML factors on a European level.

We consider both macroeconomic and portfolio-specific variables as potential instruments for conditional alphas and betas because of their documented predictive power for returns. Macroeconomic variables shown to predict returns include the default spread (DEF; Keim and Stambaugh, 1986), the risk-free rate $\left(\mathrm{R}_{\mathrm{F}}\right.$; Fama and Schwert, 1977) and the term spread (TERM; Fama and French, 1989). The default spread is defined as the yield spread between Moody's Baa- and Aaa-corporate bonds and the term spread as the spread between ten-year German government bonds and the three-month FIBOR rate. The theoretical motivation for choosing the portfolio-specific variables size and book-to-market as instruments is given by Gomes et al. (2003), who show that the ability of size and $\mathrm{B} / \mathrm{M}$ to explain the cross-section of returns is due to their correlation with the true conditional market beta. In particular, they demonstrate that size captures the component of a firm's systematic risk related to its growth options whereas the book-to-market ratio is a measure of the risk of the firm's assets in place.

Jagannathan and Wang (1996) stress that, although several variables may help predict the business cycle, we have to restrict ourselves to a small number of such variables to ensure precision in the estimation of the model parameters. We use the adjusted $\mathrm{R}^{2}$ and Akaike information criterion to determine the optimal set of conditioning variables. These model selection criteria prefer the default spread, size, B/M and interaction terms between default spread and size and between default spread and B/M as instruments for conditional betas. The interaction terms allow the relation between risk and portfolio characteristics to vary over time as a function of the business cycle, consistent with the economic motivation for conditional asset pricing models. For modelling conditional alphas the information criteria indicate that including the default spread, risk-free rate, term spread and the two portfolio-specific instruments size and B/M leads to the best model fit. Apart from statistical considerations, choosing a different set of conditioning variables for alpha and beta is also in line with Avramov and Chordia (2006).

For every portfolio the following non-risk characteristics are calculated each month as possible determinants of the cross-section of risk-adjusted returns:

- SIZE: average market value of equity of the firms in the portfolio in billions of euros, included to assess the significance of the size effect

- B/M: sum of book equity for the firms in the portfolio divided by the sum of their market capitalization, included to examine the significance of the value premium.

- RET2-3, RET4-6, RET7-12: cumulative portfolio returns over the second through third, fourth through sixth, and seventh through twelfth months prior to the current month, respectively, included to analyze the significance of the relation between past performance and expected returns.

Because the distributions of these characteristics display considerable skewness we use their logarithmic transformations. Following Brennan et al. (1998), in the cross-sectional analysis we normalize the characteristics by expressing them as deviations from their cross-sectional means. Thus, for the average portfolio the value of the characteristics is zero. Consequently, under both the null hypothesis that non-risk characteristics do not have significant incremental power for capturing the cross-section of returns and the alternative hypothesis that they do have significant explanatory power, the return on the average portfolio is determined by its risk characteristics only. 


\section{Empirical Results}

\subsection{Time-series evidence on the unconditional three-factor model}

As a benchmark we first consider time-series regression results for the unconditional three-factor model, shown in Table 3. The explanatory power of the model in terms of adjusted $\mathrm{R}^{2}$ is high, ranging from $73 \%$ to $89 \%$. In fact, for our sample period the three-factor model has higher explanatory power in Europe than in the USA. This result lends support to the assumption that European financial markets are fairly integrated and justifies our use of a pan-European version of the model.

The intercept in the time-series regressions is the pricing error, which represents the portion of the excess portfolio return left unexplained by the risk factors in the model. If the three-factor model completely explains the cross-section of average returns the intercepts in the time-series regressions should all be zero. The empirical results show that the intercept is significant at the $5 \%$ level for four out of 25 portfolios.

Notably, the pricing error of the small-growth portfolio is significantly positive and large in economic terms, whereas in the USA this portfolio produces significant negative pricing errors (Fama and French, 1996). Thus, the small-growth anomaly we observe in Europe is exactly opposite to that in the USA. Moreover, Fama and French (1998) document a value premium in international data. However, their sample period (19741994) excludes the tech bubble in the late nineties. A subsample analysis confirms that the alphas for the small-growth portfolios $\mathrm{S} 1 / \mathrm{B} 1$ and $\mathrm{S} 1 / \mathrm{B} 2$ are higher in the second half of our sample period (1994-2002), which is not in the sample of Fama and French (1998). ${ }^{7}$ This is illustrated in Figure 1, which displays the evolution through time of alphas in the conditional three-factor model for the five portfolios in the smallest quintile. As noted by Cochrane (2005), in the USA the value premium has also decreased substantially during the 1990s. Consistent with these explanations, a closer look at the composition of the S1/B1 portfolio shows that it includes many start-up companies, which are relatively small and have low book-to-market ratios and whose stock prices soared during the tech bubble. Another striking feature of this portfolio is the high first order autocorrelation of its monthly return $(\rho=0.41)$, which could be due to thin trading. Therefore, part of the high return on this portfolio might also be a compensation for liquidity risk.

In general, several pricing errors are quite large in absolute value, particularly for some of the small portfolios. This is confirmed by the Gibbons et al. (1989) test, which strongly rejects the hypothesis that the intercepts for the 25 size-B/M portfolios are jointly equal to zero. These results motivate the extension of the model to conditional specifications.

\subsection{Predictability of size and book-to-market portfolio returns}

Before turning to the analysis of the conditional three-factor model, we first examine the time-series relation between expected returns on the 25 size-B/M portfolios and the predictive variables $R_{F}$, DEF, TERM, SIZE and B/M. Table 4 summarizes time-series regressions of portfolio returns on this set of lagged variables. The results confirm that

\footnotetext{
${ }^{7}$ In particular, for the subperiod February 1986-June 1994, the alpha of portfolio S1/B1 is 1.05, whereas for the subperiod July 1994-June 2002 alpha equals 1.72.
} 
Table 3

Unconditional three-factor model regressions

This table reports parameter estimates for unconditional least squares three-factor regressions

$$
r_{i t}=\alpha_{i}+\beta_{i} r_{M t}+\delta_{i} S M B_{t}+\varphi_{i} H M L_{t}+\varepsilon_{i t} .
$$

Monthly excess returns on 25 size-B/M portfolios are regressed on a constant, the market premium $\mathrm{R}_{\mathrm{M}}$ and SMB and HML. RMSE is the root mean squared pricing error. \# $>|2|$ denotes the number of t-statistics larger than 2 in absolute value. GRS F is the Gibbons, Ross and Shanken (1989) test statistic for the null hypothesis that the intercepts in the regressions for the 25 size- $\mathrm{B} / \mathrm{M}$ portfolios are jointly equal to zero.

$$
G R S=\frac{T-N-K}{N}\left[1+E_{T}(f)^{\prime} \hat{\Omega}^{-1} E_{T}(f)\right]^{-1} \hat{\alpha}^{\prime} \hat{\Sigma}^{-1} \hat{\alpha} \sim F_{N, T-N-K},
$$

where $T$ is the number of months, $N$ the number of portfolios, $K$ the number of factors $f, \alpha$ the vector

\begin{tabular}{|c|c|c|c|c|c|c|c|c|c|}
\hline Portfolio & $\alpha$ & $\beta$ & $\delta$ & $\varphi$ & $\mathrm{t}(\alpha)$ & $\mathrm{t}(\beta)$ & $\mathrm{t}(\delta)$ & $\mathrm{t}(\varphi)$ & Adj. $R^{2}$ \\
\hline $\mathrm{S} 1 / \mathrm{B} 1$ & 1.47 & 1.24 & 1.73 & -1.03 & 4.51 & 18.21 & 12.42 & -10.92 & 0.74 \\
\hline $\mathrm{S} 1 / \mathrm{B} 2$ & 0.38 & 1.04 & 1.05 & -0.20 & 1.62 & 21.11 & 10.42 & -2.93 & 0.73 \\
\hline S1/B3 & -0.19 & 0.92 & 0.90 & 0.15 & -0.94 & 21.68 & 10.38 & 2.50 & 0.73 \\
\hline $\mathrm{S} 1 / \mathrm{B} 4$ & 0.10 & 0.93 & 0.81 & 0.32 & 0.60 & 26.50 & 11.30 & 6.57 & 0.81 \\
\hline S1/B5 & 0.15 & 1.09 & 1.06 & 0.59 & 0.80 & 28.25 & 13.41 & 10.97 & 0.84 \\
\hline $\mathrm{S} 2 / \mathrm{B} 1$ & 0.25 & 1.10 & 1.22 & -0.69 & 1.34 & 28.25 & 15.37 & -12.72 & 0.85 \\
\hline $\mathrm{S} 2 / \mathrm{B} 2$ & -0.07 & 0.97 & 0.94 & -0.09 & -0.45 & 30.52 & 14.54 & -2.11 & 0.84 \\
\hline $\mathrm{S} 2 / \mathrm{B} 3$ & -0.24 & 0.91 & 0.81 & 0.21 & -1.68 & 30.85 & 13.53 & 5.08 & 0.85 \\
\hline S2/B4 & 0.05 & 0.90 & 0.77 & 0.39 & 0.38 & 31.95 & 13.40 & 9.93 & 0.86 \\
\hline S2/B5 & 0.24 & 0.99 & 0.78 & 0.69 & 1.53 & 30.31 & 11.72 & 15.19 & 0.86 \\
\hline $\mathrm{S} 3 / \mathrm{B} 1$ & -0.21 & 1.03 & 0.92 & -0.44 & -1.34 & 30.83 & 13.48 & -9.55 & 0.85 \\
\hline S3/B2 & -0.30 & 0.95 & 0.68 & 0.13 & -2.38 & 36.19 & 12.79 & 3.45 & 0.88 \\
\hline S3/B3 & -0.40 & 0.95 & 0.64 & 0.23 & -2.88 & 32.82 & 10.84 & 5.64 & 0.85 \\
\hline S3/B4 & -0.02 & 0.99 & 0.57 & 0.40 & -0.12 & 33.21 & 9.28 & 9.60 & 0.86 \\
\hline S3/B5 & 0.20 & 1.00 & 0.83 & 0.68 & 1.17 & 28.14 & 11.47 & 13.82 & 0.84 \\
\hline $\mathrm{S} 4 / \mathrm{B} 1$ & -0.23 & 1.07 & 0.66 & -0.45 & -1.55 & 34.93 & 10.61 & -10.59 & 0.88 \\
\hline $\mathrm{S} 4 / \mathrm{B} 2$ & -0.30 & 0.93 & 0.38 & 0.08 & -2.47 & 37.36 & 7.39 & 2.23 & 0.88 \\
\hline S4/B3 & -0.13 & 0.94 & 0.40 & 0.25 & -0.93 & 32.35 & 6.75 & 6.32 & 0.85 \\
\hline S4/B4 & 0.12 & 0.99 & 0.33 & 0.44 & 0.82 & 32.84 & 5.40 & 10.62 & 0.86 \\
\hline S4/B5 & 0.23 & 1.04 & 0.43 & 0.60 & 1.29 & 28.27 & 5.71 & 11.77 & 0.82 \\
\hline S5/B1 & 0.21 & 0.99 & -0.28 & -0.51 & 1.29 & 29.78 & -4.18 & -11.06 & 0.85 \\
\hline S5/B2 & -0.01 & 0.95 & -0.13 & -0.03 & -0.11 & 38.97 & -2.72 & -0.92 & 0.89 \\
\hline S5/B3 & 0.01 & 1.00 & -0.16 & 0.18 & 0.08 & 34.32 & -2.77 & 4.52 & 0.86 \\
\hline S5/B4 & 0.13 & 1.00 & -0.11 & 0.33 & 0.90 & 33.96 & -1.89 & 8.01 & 0.86 \\
\hline S5/B5 & 0.14 & 1.08 & -0.29 & 0.63 & 0.62 & 22.74 & -3.03 & 9.59 & 0.76 \\
\hline RMSE & 0.36 & & & & & & & & \\
\hline GRS F & 2.47 & & & $\#>|2|$ & 4 & 25 & 24 & 24 & 0.84 \\
\hline P-value & 0.0003 & & & & & & & & \\
\hline
\end{tabular}
of intercepts, $\Omega$ the covariance matrix of the factors, and $\Sigma$ the covariance matrix of $\alpha$. 

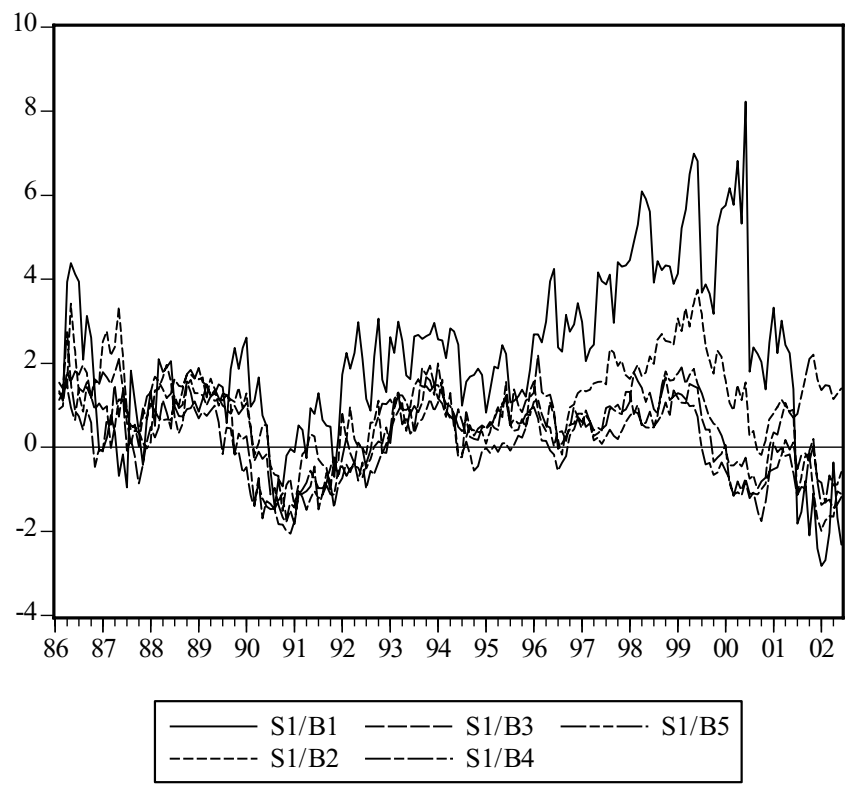

Fig. 1. Conditional alphas for portfolios in smallest size quintile

This figure plots the evolution through time of conditional alphas for the five portfolios in the smallest size quintile. The instruments in the specification of the conditional alpha are the risk-free rate, default spread, term spread, portfolio size, and portfolio B/M. The specification for the conditional risk loadings includes the default spread, portfolio size and book-to-market, and interaction terms between default spread and size and between default spread and B/M. S1/B1 is the portfolio with smallest size and lowest book-to-market ratio and S1/B5 denotes the portfolio with smallest size and highest book-to-market ratio. The sample period is February 1986 through June 2002.

the variables are significant predictors of time variation in expected portfolio returns. The explanatory power of the predictive variables in terms of adjusted $\mathrm{R}^{2}$ ranges from $2 \%$ for some of the large-cap portfolios to $11 \%$ for some small-cap portfolios, consistent with results documented for the USA by Ferson and Harvey (1999). Moreover, the coefficients on the predictors vary considerably across portfolios, suggesting that they do have explanatory power for the cross-section of portfolio returns. Table 4 also reports regression results for the three Fama-French factors. The predictive power for $R_{M}$ and SMB is in line with that for the 25 portfolios. However, HML seems not very predictable, suggesting that it contributes little to explaining time-varying expected returns.

\subsection{Time-varying betas in the three-factor model}

Conditional asset pricing theory asserts that the significant relation between the predictors and expected returns should disappear when their role as determinant of timevarying risk is recognized. In contrast, the mispricing view argues that their predictive power will persist even when fluctuations in risk have been taken into account. Thus, in order to distinguish between both views, we model time variation in risk loadings as a function of the instruments and assess whether the alphas produced by conditional specifications of the Fama-French three-factor model are constant. 


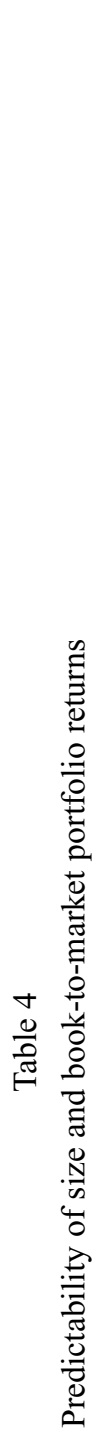

责

Ir

然政

\%

至

tr.t.

需

i

년 을

要雪

即

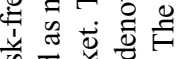

踏这

要

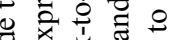

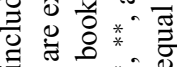

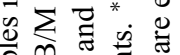

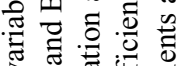

त事

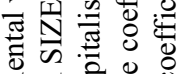

듕요

के

品离壳

o

하응

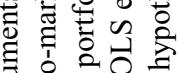

要究 0

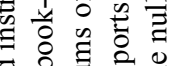

응

品응

要过

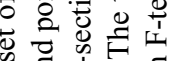

㛡的

동웡

च क 0 .

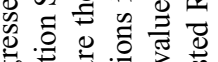

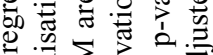

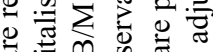

要问

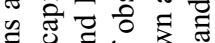

可

式空造

论

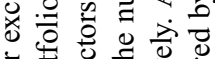

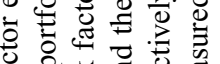

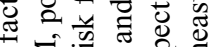
¿

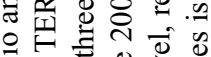

응 吾

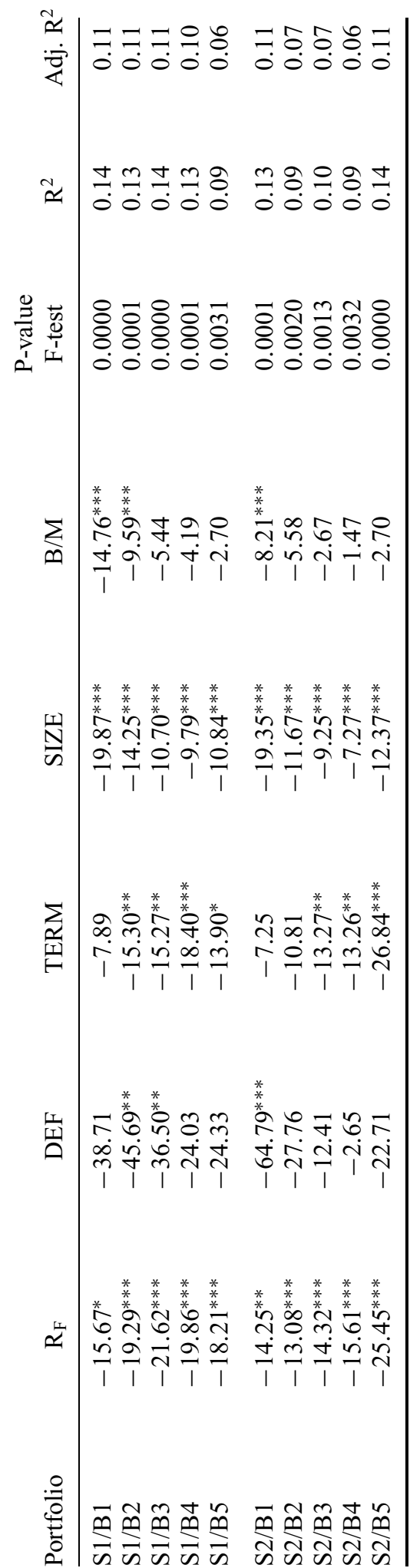




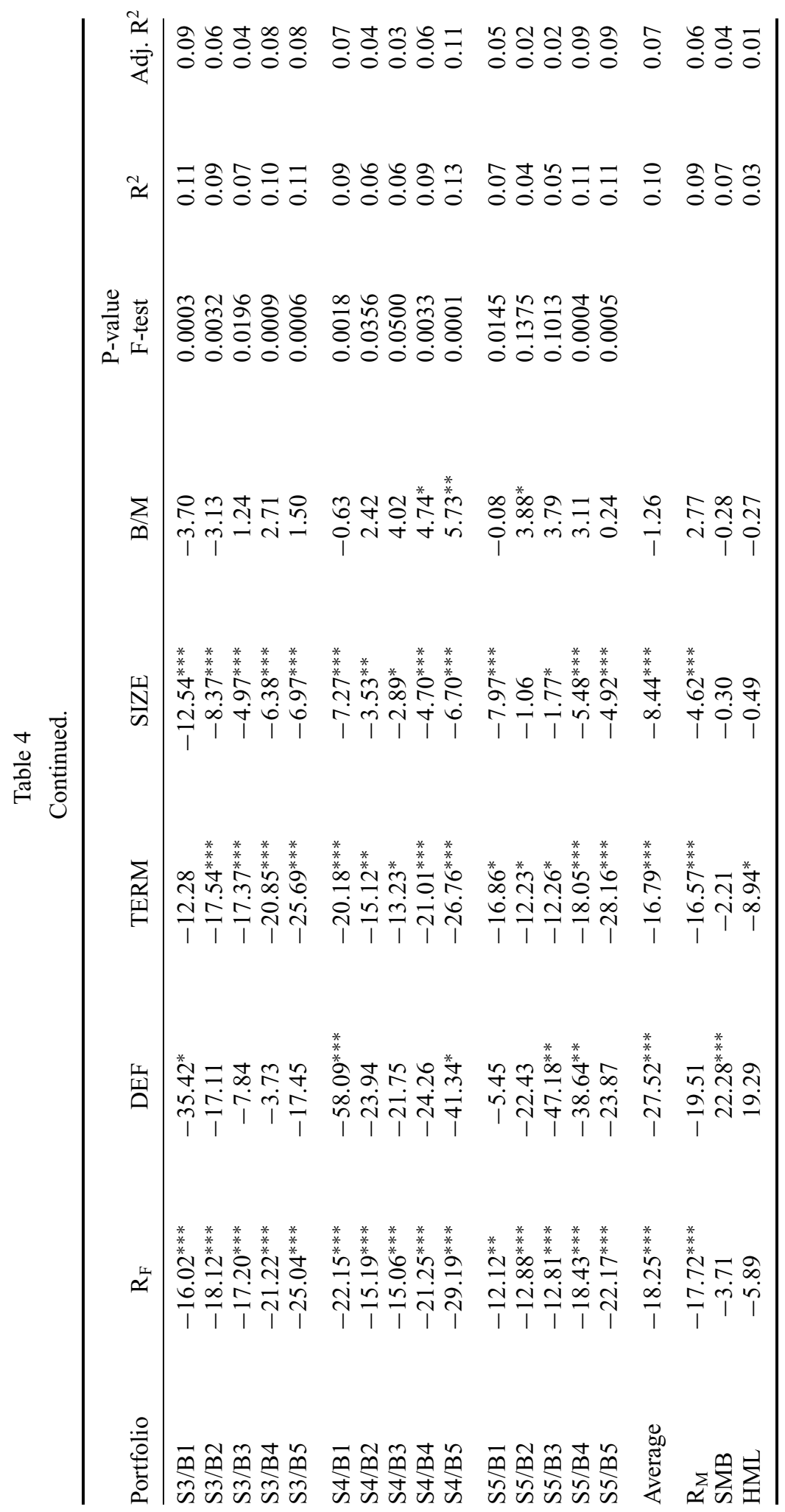


Table 5

Time-varying betas in the three-factor model

Value-weighted excess returns on 25 size-B/M portfolios are regressed on a constant, lagged instruments, the three Fama-French risk factors and interaction terms between these factors and the lagged instruments. The second column shows the adjusted R-squared for a constant alpha, constant betas model, while the third column presents this statistic for a constant alpha, time-varying betas model. The fourth column reports the p-value of an F-test comparing the R-squared of these two models to test for time-varying betas. The last three columns contain results for a similar analysis but in this case the alphas are assumed to be time-varying. The sample period is February 1986 through June 2002. Bonferroni is the Bonferroni adjusted p-value for a joint test across portfolios of the null hypothesis that betas are constant. $\#<0.05$ is the number of p-values below 0.05 .

\begin{tabular}{|c|c|c|c|c|c|c|}
\hline \multirow[b]{2}{*}{ Portfolio } & \multicolumn{3}{|c|}{ Constant alphas } & \multicolumn{3}{|c|}{ Time-varying alphas } \\
\hline & $\begin{array}{c}\text { Adj. } \mathrm{R}^{2} \\
\text { constant betas }\end{array}$ & $\begin{array}{c}\text { Adj. } \mathrm{R}^{2} \\
\text { dynamic betas }\end{array}$ & $\begin{array}{c}\text { P-value } \\
\text { F-test }\end{array}$ & $\begin{array}{c}\text { Adj. } \mathrm{R}^{2} \\
\text { constant betas }\end{array}$ & $\begin{array}{c}\text { Adj. } \mathrm{R}^{2} \\
\text { dynamic betas }\end{array}$ & $\begin{array}{c}\text { P-value } \\
\text { F-test }\end{array}$ \\
\hline $\mathrm{S} 1 / \mathrm{B} 1$ & 0.740 & 0.796 & 0.000 & 0.793 & 0.825 & 0.000 \\
\hline $\mathrm{S} 1 / \mathrm{B} 2$ & 0.726 & 0.773 & 0.000 & 0.753 & 0.783 & 0.001 \\
\hline S1/B3 & 0.733 & 0.758 & 0.005 & 0.755 & 0.772 & 0.024 \\
\hline S1/B4 & 0.805 & 0.832 & 0.000 & 0.819 & 0.855 & 0.000 \\
\hline $\mathrm{S} 1 / \mathrm{B} 5$ & 0.839 & 0.845 & 0.094 & 0.846 & 0.851 & 0.139 \\
\hline $\mathrm{S} 2 / \mathrm{B} 1$ & 0.851 & 0.865 & 0.003 & 0.865 & 0.872 & 0.054 \\
\hline $\mathrm{S} 2 / \mathrm{B} 2$ & 0.844 & 0.870 & 0.000 & 0.850 & 0.872 & 0.000 \\
\hline $\mathrm{S} 2 / \mathrm{B} 3$ & 0.846 & 0.878 & 0.000 & 0.848 & 0.886 & 0.000 \\
\hline $\mathrm{S} 2 / \mathrm{B} 4$ & 0.861 & 0.873 & 0.007 & 0.858 & 0.874 & 0.001 \\
\hline $\mathrm{S} 2 / \mathrm{B} 5$ & 0.860 & 0.881 & 0.000 & 0.871 & 0.890 & 0.000 \\
\hline $\mathrm{S} 3 / \mathrm{B} 1$ & 0.855 & 0.878 & 0.000 & 0.863 & 0.881 & 0.000 \\
\hline $\mathrm{S} 3 / \mathrm{B} 2$ & 0.877 & 0.894 & 0.000 & 0.875 & 0.892 & 0.000 \\
\hline $\mathrm{S} 3 / \mathrm{B} 3$ & 0.855 & 0.887 & 0.000 & 0.857 & 0.886 & 0.000 \\
\hline $\mathrm{S} 3 / \mathrm{B} 4$ & 0.861 & 0.882 & 0.000 & 0.864 & 0.884 & 0.000 \\
\hline $\mathrm{S} 3 / \mathrm{B} 5$ & 0.842 & 0.867 & 0.000 & 0.846 & 0.869 & 0.000 \\
\hline $\mathrm{S} 4 / \mathrm{B} 1$ & 0.877 & 0.898 & 0.000 & 0.884 & 0.901 & 0.000 \\
\hline S4/B2 & 0.878 & 0.886 & 0.021 & 0.879 & 0.884 & 0.077 \\
\hline S4/B3 & 0.847 & 0.879 & 0.000 & 0.853 & 0.878 & 0.000 \\
\hline S4/B4 & 0.856 & 0.883 & 0.000 & 0.858 & 0.885 & 0.000 \\
\hline S4/B5 & 0.825 & 0.857 & 0.000 & 0.832 & 0.861 & 0.000 \\
\hline S5/B1 & 0.849 & 0.881 & 0.000 & 0.850 & 0.882 & 0.000 \\
\hline S5/B2 & 0.889 & 0.910 & 0.000 & 0.888 & 0.909 & 0.000 \\
\hline S5/B3 & 0.862 & 0.897 & 0.000 & 0.870 & 0.900 & 0.000 \\
\hline S5/B4 & 0.861 & 0.899 & 0.000 & 0.866 & 0.900 & 0.000 \\
\hline S5/B5 & 0.757 & 0.851 & 0.000 & 0.789 & 0.851 & 0.000 \\
\hline Bonferroni & & & 0.000 & & & 0.000 \\
\hline$\#<0.05$ & & & 24 & & & 22 \\
\hline
\end{tabular}

Table 5 reports regression results for the conditional three-factor model. The table shows the explanatory power of the model in terms of adjusted $\mathrm{R}^{2}$. It also provides p-values of F-tests performed to investigate whether the lagged instruments pick up significant variation in risk loadings. The null hypothesis for these tests is that the 
loadings on the interaction terms between the risk factors and the conditioning variables are jointly equal to zero. P-values are below $5 \%$ for 24 portfolios in the constant alpha case and 22 portfolios when alpha is allowed to vary. The joint Bonferroni test strongly rejects the null hypothesis of constant betas. ${ }^{8}$ Thus, betas exhibit strong time variation, which can be captured by a set of lagged instruments. For most portfolios the adjusted $\mathrm{R}^{2}$ rises considerably when risk loadings are allowed to fluctuate over time. The explanatory power of the model also increases for many portfolios when time variation in alphas is modelled. This suggests that alphas may not be constant over time, even in a model with time-varying betas. We test this hypothesis in the next section.

\subsection{Conditional alphas in the three-factor model}

In Table 6 results are shown for tests of the hypothesis that pricing errors are zero and for the weaker hypothesis that alphas are constant through time. We test whether conditional alphas are zero by performing an F-test for the hypothesis that the intercept and the slopes on the lagged instruments are jointly equal to zero. Columns two and three show that the hypothesis of a zero conditional alpha is rejected at the $5 \%$ level for 15 portfolios in the constant beta case and 12 portfolios in the conditional three-factor model. The Bonferroni adjusted p-value for a joint test across portfolios is 0.000 .

When testing whether alphas are constant the null hypothesis of the F-test is that the instruments for the conditional alpha can be excluded from the model. Results reported in column four indicate that the weaker hypothesis that alphas are constant is rejected at the $5 \%$ level for 15 of the 25 portfolios in a model with constant betas. This implies that the static three-factor model does not adequately explain the dynamics of conditional expected returns. In contrast, column five shows that when betas are allowed to vary the null hypothesis is rejected for only eight portfolios. Thus, the ability of the instruments to predict mispricing diminishes when allowing for time variation in factor loadings. Nevertheless, the joint Bonferroni test still rejects the null hypothesis of constant alphas.

In sum, the main conclusion drawn from the time-series analysis is that betas are time-varying and that these fluctuations in risk can be picked up by a combination of macroeconomic and portfolio-specific instruments. Conditional specifications of the three-factor model outperform their unconditional counterpart in explaining time variation in expected returns. However, even after taking time variation in betas into account the model does not fully explain conditional expected returns on the portfolios. Predictable patterns in pricing errors remain, consistent with results documented by Ferson and Harvey (1999) for the USA but contradicting the conclusion of Lewellen (1999) that modelling time variation in risk eliminates the predictive power of B/M.

\subsection{Cross-sectional evidence on the three-factor model}

Having found evidence of substantial fluctuations in betas we now examine whether incorporating time variation in risk is sufficient to eliminate the cross-sectional explanatory power of size, $\mathrm{B} / \mathrm{M}$ and momentum variables. The cross-sectional analysis is useful to identify the sources of the mispricing detected by the time-series regressions. Following Avramov and Chordia (2006), we evaluate the pricing abilities of the model

\footnotetext{
${ }^{8}$ The Bonferroni correction is a multiple-comparison adjustment for dependence across portfolios.
} 
Table 6

Time-varying alphas in the three-factor model

The second column in this table reports the p-value of an F-test for the hypothesis that the conditional alpha is zero in the constant beta three-factor model while in column three p-values are shown for the same hypothesis when betas are allowed to vary over time as a function of instrumental variables. Columns four and five report p-values for the null hypothesis that alpha is constant in the constant beta three-factor model and a three-factor model with time-varying betas, respectively. The sample period is February 1986 through June 2002. Bonferroni is the Bonferroni adjusted p-value for a joint test across portfolios. $\#<0.05$ is the number of p-values below 0.05 .

\begin{tabular}{lcccc}
\hline Portfolio & $\begin{array}{c}\text { Test zero cond. } \alpha \\
\text { (constant } \beta \text { ) }\end{array}$ & $\begin{array}{c}\text { Test zero cond. } \alpha \\
\text { (time-varying } \beta \text { ) }\end{array}$ & $\begin{array}{c}\text { Test constant } \alpha \\
\text { (constant } \beta \text { ) }\end{array}$ & $\begin{array}{c}\text { Test constant } \alpha \\
\text { (time-varying } \beta \text { ) }\end{array}$ \\
\hline S1/B1 & 0.000 & 0.000 & 0.000 & 0.000 \\
S1/B2 & 0.000 & 0.001 & 0.000 & 0.019 \\
S1/B3 & 0.001 & 0.017 & 0.001 & 0.009 \\
S1/B4 & 0.004 & 0.000 & 0.002 & 0.000 \\
S1/B5 & 0.024 & 0.031 & 0.017 & 0.038 \\
S2/B1 & 0.000 & 0.005 & 0.000 & 0.017 \\
S2/B2 & 0.055 & 0.296 & 0.034 & 0.205 \\
S2/B3 & 0.124 & 0.003 & 0.204 & 0.004 \\
S2/B4 & 0.956 & 0.351 & 0.923 & 0.250 \\
S2/B5 & 0.001 & 0.001 & 0.001 & 0.003 \\
S3/B1 & 0.007 & 0.136 & 0.007 & 0.084 \\
S3/B2 & 0.268 & 0.331 & 0.832 & 0.981 \\
S3/B3 & 0.011 & 0.012 & 0.130 & 0.707 \\
S3/B4 & 0.154 & 0.265 & 0.096 & 0.179 \\
S3/B5 & 0.063 & 0.078 & 0.061 & 0.158 \\
S4/B1 & 0.007 & 0.127 & 0.009 & 0.078 \\
S4/B2 & 0.044 & 0.198 & 0.222 & 0.768 \\
S4/B3 & 0.026 & 0.391 & 0.020 & 0.558 \\
S4/B4 & 0.220 & 0.304 & 0.181 & 0.215 \\
S4/B5 & 0.020 & 0.026 & 0.020 & 0.062 \\
S5/B1 & 0.270 & 0.073 & 0.313 & 0.256 \\
S5/B2 & 0.904 & 0.804 & 0.828 & 0.717 \\
S5/B3 & 0.009 & 0.106 & 0.004 & 0.064 \\
S5/B4 & 0.051 & 0.049 & 0.039 & 0.155 \\
S5/B5 & 0.000 & 0.031 & 0.000 & 0.374 \\
Bonferroni & 0.000 & 0.000 & 0.000 & 0.001 \\
\# 0.05 & 15 & 12 & 15 & 8 \\
\hline & & & &
\end{tabular}

by looking at the significance of Fama-MacBeth parameter estimates for the size, bookto-market and momentum variables. In addition, we use the time-series average of the cross-sectional adjusted $\mathrm{R}^{2}$ as an informal measure of model performance. In short, a low $\mathrm{R}^{2}$ and insignificant coefficients can be interpreted as support for the model used to risk-adjust returns, since these imply that the explanatory power of the portfolio characteristics is limited. In contrast, a high average adjusted $\mathrm{R}^{2}$ and significant FM 
coefficient estimates suggest that size, book-to-market and momentum effects are not adequately captured by the asset pricing model. ${ }^{9}$

We start off by considering results for FM regressions of raw returns (i.e. not adjusted for risk) on a constant and the portfolio characteristics size, $\mathrm{B} / \mathrm{M}$ and the past return variables RET2-3, RET4-6 and RET7-12. Average cross-sectional regression coefficients are reported in column two of Table 7 along with their t-ratios and the time-series average of the monthly adjusted $\mathrm{R}^{2}$. The intercept is significant at a $5 \%$ level, suggesting the presence of time-invariant pricing errors. The coefficient on size is negative and significant. Thus, a size effect is present in the cross-section of European stock returns, which confirms earlier results by Heston et al. (1999). The book-tomarket coefficient is positive but insignificant, which means that the value premium is absent. Loadings on all three past return variables are positive and significant. Strong momentum effects in size-B/M portfolios have also been found in the USA by Lewellen (2002). The average adjusted $\mathrm{R}^{2}$ is $38.0 \%$, indicating that the characteristics explain a substantial fraction of cross-sectional variation in returns.

In order to examine whether the high explanatory power and significance of the size and momentum variables persist when cross-sectional differences in risk are taken into account, we risk-adjust returns in first-pass three-factor regressions. FM parameter estimates are shown in column three. The coefficient on size is no longer significant at the $5 \%$ level. The intercept has also become insignificant and the adjusted $\mathrm{R}^{2}$ has fallen sharply to $12.1 \%$. However, all three momentum variables are still significant, confirming the finding of Fama and French (1996) that their three-factor model does not capture the momentum effect.

Results for the conditional Fama-French model are presented in column four. As in the case of the unconditional model, coefficients on both the size characteristic and the $\mathrm{B} / \mathrm{M}$ variable are insignificant. More important, however, is that the loadings on all three past return variables are still significant at the 5\% level, suggesting that even a dynamic three-factor model cannot capture the momentum effect. Furthermore, although the conditional model produces the lowest average adjusted $\mathrm{R}^{2}$, it still exceeds $10 \%$, reflecting the strong cross-sectional predictive power of the past return variables.

In conclusion, results presented in Table 7 indicate that the Fama-French model eliminates the cross-sectional explanatory power of size. Allowing for time variation in risk loadings only leads to a marginal improvement in the pricing ability of the model specification we consider. In particular, both static and dynamic three-factor models are unable to explain the impact of past returns on the cross-section of portfolio returns.

\subsection{Business cycle risk and momentum}

Chordia and Shivakumar (2002) suggest that in the USA return momentum is related to business cycle variations. In contrast, Griffin, Ji, and Martin (2003) present international evidence that momentum profits cannot be explained by macroeconomic risk factors. However, neither study considers the relation between momentum and macroeconomic state variables in a framework that controls for time-varying risk exposures. Therefore, Avramov and Chordia (2006) specify a conditional asset pricing model in which alpha

\footnotetext{
${ }^{9}$ As noted by Avramov and Chordia (2006), a zero $\mathrm{R}^{2}$ does not necessarily imply that the model completely explains the cross-section of average portfolio returns. A significant intercept would imply that the model produces time-invariant pricing errors unrelated to the portfolio characteristics.
} 


\section{Table 7}

Fama-MacBeth regressions of raw returns and three-factor risk-adjusted returns

This table reports Fama-MacBeth coefficient estimates. In the second column, the dependent variable is the excess portfolio return unadjusted for risk. In the third column the dependent variable is the excess return risk-adjusted using the Fama-French three-factor model with constant alphas and betas. In the fourth column the dependent variable is the excess portfolio return risk-adjusted using a conditional three-factor model with constant alphas, where factor loadings are scaled by the default spread, size, book-to-market and interaction terms between default spread and size and $\mathrm{B} / \mathrm{M}$,

$$
\beta_{i k t}=\beta_{i k 1}+\beta_{i k 2} D E F_{t}+\left(\beta_{i k 3}+\beta_{i k 4} D E F_{t}\right) S I Z E_{i t}+\left(\beta_{i k 5}+\beta_{i k 6} D E F_{t}\right) B / M_{i t},
$$

where $D E F$ is the default spread and SIZE and $B / M$ are the logarithm of portfolio market capitalisation in billions of euros and the logarithm of portfolio book-to-market ratio, respectively.

In the fifth and sixth columns alphas are time-varying and a function of macroeconomic variables,

$$
\alpha_{i t}=\alpha_{i 0}+\alpha_{i 1} D E F_{t}+\alpha_{i 2} R_{F t}+\alpha_{i 3} T_{E R M_{t}},
$$

where $R_{F}$ is the risk-free rate and TERM is the term spread. The dependent variable in the fifth and sixth column is $\alpha_{i 0}$, the part of the risk-adjusted return that is unrelated to business cycle effects.

Portfolio characteristics are the regressors in the cross-sectional regressions. SIZE and B/M are expressed as logarithms of market capitalisation and book-to-market, respectively, and RET2-3, RET46 and RET7-12 are cumulative past returns. All five characteristics are measured as deviations from their cross-sectional mean in each month. The sample period is February 1986 through June 2002. Adj. $\mathrm{R}^{2}$ is the time-series average of the monthly adjusted $\mathrm{R}^{2}$. T-statistics are reported in parentheses.

\begin{tabular}{lcccccc}
\hline & & \multicolumn{2}{c}{ Constant Alpha } & & \multicolumn{2}{c}{ Time-Varying Alpha } \\
\cline { 3 - 4 } & Raw Return & Constant $\beta$ & Dynamic $\beta$ & & Constant $\beta$ & Dynamic $\beta$ \\
\hline Intercept & 0.776 & 0.077 & 0.057 & & 0.211 & 0.132 \\
& $(2.190)$ & $(0.879)$ & $(0.705)$ & & $(1.864)$ & $(1.621)$ \\
SIZE & -0.093 & -0.027 & -0.024 & & -0.019 & -0.014 \\
& $(-1.970)$ & $(-0.978)$ & $(-1.027)$ & & $(-0.536)$ & $(-0.520)$ \\
B/M & 0.006 & -0.066 & -0.005 & & 0.013 & 0.040 \\
& $(0.051)$ & $(-1.106)$ & $(-0.084)$ & & $(0.307)$ & $(0.702)$ \\
RET2-3 & 0.044 & 0.036 & 0.040 & & 0.042 & 0.045 \\
& $(2.934)$ & $(2.372)$ & $(2.909)$ & & $(3.019)$ & $(3.457)$ \\
RET4-6 & 0.029 & 0.028 & 0.027 & & 0.029 & 0.029 \\
& $(2.308)$ & $(2.164)$ & $(2.293)$ & & $(2.278)$ & $(2.434)$ \\
RET7-12 & 0.044 & 0.041 & 0.036 & & 0.040 & 0.036 \\
& $(5.623)$ & $(5.111)$ & $(4.920)$ & & $(5.034)$ & $(4.860)$ \\
\hline Adj. R ${ }^{2}$ & 0.380 & 0.121 & 0.106 & & 0.120 & 0.105 \\
\hline
\end{tabular}

is a linear function of business cycle variables. They find that in this model the predictive power of momentum variables becomes insignificant and conclude that a yet undiscovered risk factor related to the business cycle may explain the momentum effect in the USA, supporting the results of Chordia and Shivakumar (2002).

It is interesting to see whether we can confirm these findings using the 25 European size-B/M portfolios as test assets. Following the approach of Avramov and Chordia 
(2006), we allow alpha to vary over time as a function of three business cycle variables: risk-free rate, default spread, and term spread. The dependent variable in the crosssectional regressions is then the part of mispricing unrelated to the business cycle.

The FM estimates in columns five and six of Table 7 show the relation between the portfolio characteristics and the fraction of risk-adjusted returns unrelated to business cycle effects. The results in these columns indicate that all momentum variables remain significant, irrespective of whether betas are constant or time-varying. Moreover, the cross-sectional predictive power of the characteristics, measured by the adjusted $\mathrm{R}^{2}$, is almost identical to the values reported in columns three and four. In sum, we find no evidence that momentum is related to business cycle variations in a way that can be captured by the conditional three-factor model we consider. These findings support those documented by Griffin, Li, and Martin (2003): outside the USA macroeconomic factors do not seem to explain return momentum.

\subsection{Robustness of empirical results}

As a robustness check we purge the 25 size-B/M portfolios from possible country and sector effects to determine whether our results are affected by country and/or sector tilts in the portfolios. We control for country and sector tilts by first performing crosssectional regressions of firm size and $\mathrm{B} / \mathrm{M}$ on country and sector dummies,

$$
x_{i t}=\kappa_{t}+\sum_{j=1}^{J-1} \theta_{j t} S_{i j}+\sum_{h=1}^{H-1} \psi_{h t} C_{i h}+\tau_{i t},
$$

where $x_{i t}$ is a vector that contains the size and book-to-market characteristics of firm $i$ at date $t, S_{i j}$ a sector dummy variable equal to one if firm $i$ belongs to sector $j$ and zero otherwise, and $C_{i h}$ a dummy variable that equals one if firm $i$ belongs to country $h$. By leaving out the sector (country) dummies we can purge the characteristics from country (sector) effects only. Subsequently, the vector of residuals $\tau_{i t}$ from (8) is used to sort the stocks into 25 size-B/M portfolios.

The bottom half of Table 2 reports value-weighted returns for the 25 size-B/M portfolios constructed using country- or sector-neutral characteristics. Similar to the original portfolios shown in the upper left corner, the purged portfolios exhibit a significant average size effect but insignificant value premium, although for some individual size quintiles a significant B/M effect can be observed. In general, however, returns on the country-neutral and/or sector-neutral portfolios do not deviate strongly from the returns on the original portfolios. We can confirm that using these portfolios as test assets in the empirical analysis does not alter our conclusions. ${ }^{10}$

The second check on our results deals with possible correlation between errors in the factor loadings estimated in first-pass time-series regressions and the non-risk portfolio characteristics used as predictors in the second-stage cross-sectional regression (7). Although factor loadings are correlated with the portfolio characteristics included in $P_{t}$ in equation (7), Brennan et al. (1998) argue that there is no a priori reason to believe that the errors in the estimated loadings will be correlated with the characteristics. Nevertheless, if they are not independent the cross-sectional regression coefficients on

\footnotetext{
${ }^{10}$ Results for all robustness checks are omitted in the interest of parsimony and available upon request.
} 
the portfolio characteristics will be correlated with the factor returns and consequently, the standard FM estimator will be biased.

Therefore, Brennan et al. (1998) propose to calculate a purged estimator for each of the characteristics. This estimator is unbiased when errors in the estimated factor loadings and the characteristics in $P_{t}$ are correlated, provided that factor premia are serially uncorrelated. The purged estimator is the intercept in an OLS regression of the original monthly cross-sectional parameter estimates on a constant and the time series of factor realizations $F F_{k t}$. It turns out that our empirical results are almost unchanged when the purged estimator is used instead of the standard FM estimator.

A third check is motivated by Shanken (1992), who points out that the FM procedure overstates the precision of parameter estimates in the second-stage cross-sectional regressions by ignoring estimation errors in factor loadings obtained from first-pass time-series regressions. Shanken suggests a solution for this problem that explicitly adjusts the standard errors, assuming conditional homoskedasticity of returns. Applying this correction leads to t-statistics that are only slightly lower than standard OLS tstatistics. Hence, our conclusions from the cross-sectional analysis still hold.

Fourth, instead of estimating the time-series regressions by ordinary least squares (OLS) regressions, we also perform seemingly unrelated regressions (SUR) to account for contemporaneous correlation in residuals across portfolios. However, estimation results are very similar and all main conclusions remain unchanged.

Finally, we repeat the empirical analysis for the CAPM and the Carhart (1997) fourfactor model, which adds a momentum factor to the three-factor model. As expected the three-factor model is clearly superior to the CAPM in terms of time series and crosssectional explanatory power. Although we find evidence of significant time variation in CAPM betas, a conditional CAPM is not able to capture size and momentum effects in portfolio returns. These results are consistent with findings documented by Lewellen and Nagel (2006) for the USA, who conclude that allowing for time variation in beta does little to salvage the CAPM. Results for the Carhart four-factor model are very similar to those reported for the Fama-French model. Most importantly, the Carhart model also fails to eliminate the strong momentum effects in the 25 size-B/M portfolios.

\section{Conclusion}

This paper investigates whether risk loadings in the Fama-French (1993) three-factor model are time-varying and if so, to what extent conditional specifications of the model can eliminate well-known anomalies in European stock markets. Our work is motivated by mixed empirical evidence on the performance of conditional asset pricing models in the USA. Prior research shows that several firm characteristics like size, book-to-market, and past returns have explanatory power for the cross-section of returns. Furthermore, it has been found that size, $\mathrm{B} / \mathrm{M}$ and macroeconomic variables predict significant time variation in expected returns.

We combine these findings to examine whether the predictive power of these variables is due to their association with time-varying risk, as suggested by conditional asset pricing theory, or to mispricing. Specifically, we test the ability of static and dynamic specifications of the three-factor model to price 25 size-B/M portfolios using merged data from 16 European markets, thereby providing out-of-sample empirical evidence on conditional asset pricing models.

We identify important differences between US and European data. In particular, while the size effect has vanished in the USA after its discovery, we document that it is still 
present in Europe. Moreover, in contrast to US evidence, we find that the notoriously hard to price small-growth portfolio displays significant positive pricing errors. We also show that a set of macroeconomic and portfolio-specific variables has substantial predictive power for European size-B/M portfolios. Our time-series tests reveal that these variables pick up significant time variation in risk. Conditional specifications of the three-factor model outperform their static counterpart in explaining time variation in expected returns. Nevertheless, even after allowing for fluctuations in factor loadings pricing errors for some portfolios are still significant and predictable to some extent.

In order to identify the sources of mispricing we apply the cross-sectional testing framework of Avramov and Chordia (2006). While the three-factor model captures the size effect, both static and dynamic specifications of the model fail to eliminate the strong cross-sectional predictive power of momentum variables. Conditioning does little to improve the cross-sectional pricing ability of the model. Finally, using European data we find no empirical support for the hypothesis put forward by Avramov and Chordia (2006) that momentum is related to business cycle variations. Thus, although the evidence of time-varying risk motivates the use of conditional asset pricing models, more is needed to revive modern finance.

\section{References}

Adrian, T. and Franzoni, F., 'Learning about beta: time-varying factor loadings, expected returns, and the conditional CAPM', Working Paper (HEC School of Management, 2005).

Ammann, M. and Verhofen, M., 'Testing conditional asset pricing models using a Markov Chain Monte Carlo approach', 2008, forthcoming in European Financial Management.

Ang, A. and Chen, J., 'CAPM over the long run: 1926-2001', Journal of Empirical Finance, Vol. 14, 2007, pp. 1-40.

Avramov, D. and Chordia T., 'Asset pricing models and financial market anomalies', Review of Financial Studies, Vol. 19, 2006, pp. 1001-40.

Banz, R., 'The relation between return and market value of common stocks', Journal of Financial Economics, Vol. 9, 1981, pp. 3-18.

Basu, S., 'Investment performance of common stocks in relation to their price-earnings ratios: a test of the efficient market hypothesis', Journal of Finance, Vol. 12, 1977, pp. 129-56.

Bekaert, G., Hodrick, R. and Zhang, X., 'International stock return comovements', Working Paper (Columbia University and Cornell University, 2005).

Berglund, T. and Knif, J., 'Accounting for the accuracy of beta estimates in CAPM tests on assets with time-varying risks', European Financial Management, Vol. 5, 1999, pp. 29-42.

Brennan, M., Chordia, T. and Subrahmanyam, A., 'Alternative factor specifications, security characteristics, and the cross-section of expected stock returns', Journal of Financial Economics, Vol. 49, 1998, pp. 345-73.

Carhart, M., 'On persistence in mutual fund performance', Journal of Finance, Vol. 51, 1997, pp. 1681-1714.

Chordia, T. and Shivakumar, L., 'Momentum, business cycle, and time-varying expected returns', Journal of Finance, Vol. 57, 2002, pp. 985-1019.

Cochrane, J., Asset Pricing, revised ed. (Princeton: Princeton University Press, 2005).

Daniel, K. and Titman, S., 'Evidence on the characteristics of cross sectional variation in stock returns', Journal of Finance, Vol. 52, 1997, pp. 1-33.

Eiling, E. and Gerard, B., 'Dispersion, equity returns correlations and market integration', Working Paper (Tilburg University, 2006).

Fama, E. and French, K., 'Business conditions and expected returns on stocks and bonds', Journal of Financial Economics, Vol. 25, 1989, pp. 23-49.

Fama, E. and French, K., 'The cross-section of expected stock returns', Journal of Finance, Vol. 47, 1992, pp. 427-65. 
Fama, E. and French, K., 'Common risk factors in the returns on stocks and bonds', Journal of Financial Economics, Vol. 33, 1993, pp. 3-56.

Fama, E. and French, K., 'Multifactor explanations of asset pricing anomalies', Journal of Finance, Vol. 51, 1996, pp. 55-84.

Fama, E. and French, K., 'Industry costs of equity', Journal of Financial Economics, Vol. 43, 1997, pp. 153-93.

Fama, E. and French, K., 'Value versus growth: the international evidence', Journal of Finance, Vol. 53, 1998, pp. 1975-99.

Fama, E. and French, K., 'The value premium and the CAPM', Journal of Finance, Vol. 61, 2006, pp. 2163-86.

Fama, E. and MacBeth, J., 'Risk, return and equilibrium: empirical tests', Journal of Political Economy, Vol. 71, 1973, pp. 607-36.

Fama, E. and Schwert, G., 'Asset returns and inflation', Journal of Financial Economics, Vol. 5, 1977, pp. 115-46.

Ferson, W. and Harvey, C., 'Fundamental determinants of national equity market returns: a perspective on conditional asset pricing', Journal of Banking and Finance, Vol. 21, 1998, pp. 1625-65.

Ferson, W. and Harvey, C., 'Conditioning variables and the cross section of stock returns', Journal of Finance, Vol. 54, 1999, pp. 1325-60.

Gibbons, M., Ross, S. and Shanken, J., 'A test of the efficiency of a given portfolio', Econometrica, Vol. 57, 1989, pp. 1121-52.

Gomes, J., Kogan, L. and Zhang, L., 'Equilibrium cross-section of returns', Journal of Political Economy, Vol. 111, 2003, pp. 693-732.

Griffin, J., Ji, X. and Martin, S., 'Momentum investing and business cycle risk: evidence from pole to pole', Journal of Finance, Vol. 58, 2003, pp. 2515-47.

Hansen, L. and Richard, S., 'The role of conditioning information in deducing testable restrictions implied by dynamic asset pricing models', Econometrica, Vol. 55, 1987, pp. 587-613.

Heston, S., Rouwenhorst, K. and Wessels, R., 'The role of beta and size in the cross-section of European stock returns', European Financial Management, Vol. 5, 1999, pp. 9-27.

Jagannathan, R. and Wang, Z., 'The conditional CAPM and cross-section of expected returns', Journal of Finance, Vol. 51, 1996, pp. 3-53.

Jegadeesh, N. and Titman, S., 'Returns to buying winners and selling losers: implications for stock market efficiency', Journal of Finance, Vol. 48, 1993, pp. 65-91.

Keim, D. and Stambaugh, R., 'Predicting returns in the bond and stock markets', Journal of Financial Economics, Vol. 17, 1986, pp. 357-90.

Lakonishok, J., Shleifer, A. and Vishny, R., 'Contrarian investment, extrapolation, and risk', Journal of Finance, Vol. 49, 1994, pp. 1541-78.

Lewellen, J., 'The time-series relations among expected return, risk, and book-to-market', Journal of Financial Economics, Vol. 54, 1999, pp. 5-43.

Lewellen, J., 'Momentum and autocorrelation in stock returns', Review of Financial Studies, Vol. 15, 2002, pp. 533-63.

Lewellen, J. and Nagel, S., 'The conditional CAPM does not explain asset-pricing anomalies', Journal of Financial Economics, Vol. 82, 2006, pp. 289-314.

Lewellen, J., Nagel, S. and Shanken, J., 'A skeptical appraisal of asset-pricing tests', Working Paper (Dartmouth, Stanford University and Emory University, 2007).

Petkova, R. and Zhang, L., 'Is value riskier than growth?', Journal of Financial Economics, Vol. 78, 2005, pp. 187-202.

Rouwenhorst, K., 'International momentum strategies', Journal of Finance, Vol. 53, 1998, pp. 267-84.

Santos, T. and Veronesi, P., 'Conditional betas', Working Paper (Columbia University and University of Chicago, 2004).

Schrimpf, A., Schröder, M. and Stehle, R., 'Cross-sectional tests of conditional asset pricing models: evidence from the German Stock Market', European Financial Management, Vol. 13, 2007, pp. 880-907. 
Shanken, J., 'Intertemporal asset pricing: an empirical investigation', Journal of Econometrics, Vol. 45, 1990, pp. 99-120.

Shanken, J., 'On the estimation of beta-pricing models', Review of Financial Studies, Vol. 5, 1992, pp. $1-34$.

$\mathrm{Wu}, \mathrm{X}$., 'A conditional multifactor analysis of return momentum', Journal of Banking and Finance, Vol. 26, 2002, pp. 1675-96.

Zhang, L., 'The value premium', Journal of Finance, Vol. 60, 2005, pp. 67-103. 